\title{
Essence of economic instruments for the erection of real estate
}

\author{
Lyubov Manukhina ${ }^{1, *}$, and Larisa Prykina ${ }^{1}$ \\ ${ }^{1}$ Moscow State Construction University, 26, Yaroslavskoye Shosse, 129337 Moscow, Russia
}

\begin{abstract}
When analyzing real estate construction, the following features should be taken into account: when erecting real estate, it is necessary to reflect its essence by nature and types of objects of labor that are in a stationary state (buildings, structures, land and property complexes); instruments of labor and living labor, which, on the contrary, are in constant motion with respect to objects of labor. Consequently, the efficiency of construction processes depends on the correlation of parameters characterizing immovable elements with parameters characterizing movable ones. The harmony (balance) of the results of real estate elements joint functioning should be determined with the help of technical, environmental and economic indicators, which can be measured using a single indicator - energy.
\end{abstract}

\section{Introduction}

Construction is an industrial complex that implements the creation of certain construction projects followed by the achievement of the best production and economic instruments, including environmental, genetic and social ones. The synchronization (balance) of the results of construction operations should be determined using a single commensurator, for example, consumed energy. This paper considers the unity of complex systems including organizational, economic, environmental forms of their manifestation.

In recent years scientific developments related to nature-like technologies in production, including construction, have been gaining momentum. They have reached a global understanding. So, for example, this problem was first mentioned at the 70th session of the UN General Assembly in 2015. President of the Russian Federation V. Putin expressed the following thought on this issue: "It should be about creating fundamentally new nature-like technologies that would not be harmful to the outside world, but would exist in harmony with it and would allow to restore the balance between the biosphere and the technosphere violated by man. It is indeed a planetwide challenge." [1].

The abovementioned problem cannot be solved only by taking into account individual fragments of natural, nature-like and alienated technologies. It is also necessary to find conditions for their systematization in the field of construction. Today a fragmented analysis of the productive systems effectiveness is considered separately in the field of ecology and economics using various types of commensuration $[2,3]$.

\footnotetext{
*Corresponding author: 4804107@mail.ru
} 
Fragments of the interaction of man, society, civilizations with surrounding natural environments in the following areas were well-studied [5,6,7]:

- Innovations in the construction industry and creation of systems in other fields of activity.

- Production risks.

- Stability of productive systems.

- Environmental friendliness of production.

- Cost-effectiveness of systems.

- Synergy of production.

- Cognition, creativity in nature-like technologies.

However, maximum effects cannot be achieved without the systematization of the abovementioned scientific areas.

Studies in the construction industry show that a haphazard, fragmented approach to real estate construction increases failures in these systems. Therefore, the objective is to systematize and synchronize productive factors based on a combination of production elements.

\section{Materials and methods}

Real estate construction is analyzed on the basis of a systematic description of its main parameters taking into account their life cycles. The life cycle of a construction system is associated with the quantity and quality of created production structures depending on the following [8]:

a) Environmental tools for the sustainable development of construction systems that meet the parameters of natural environments. With an increase in the quality of the materials used in productive processes $\mathrm{K}_{\mathrm{s}}$, the need for specific energy $\mathrm{K}_{\mathrm{ss}}$ decreases.

Upon reaching the ultimate state of interaction between $\mathrm{K}_{\mathrm{ss}}$ and $\mathrm{K}_{\mathrm{ss}}^{\prime}$, as well as $\mathrm{K}_{\mathrm{s}}$ and $\mathrm{K}_{\mathrm{s}}^{\prime}$ of the effects of construction products quality and quantity, the ratio of these values determines the life cycle $\mathrm{L}_{c}$ of construction elements. And, conversely, the amount of energy $\mathrm{K}_{\mathrm{s}}^{\prime}$ in the structures of construction operations and finished products, $\mathrm{K}_{\mathrm{s}}$ effect, will decrease due to the degradation of their quality and quantity (Fig. 1).

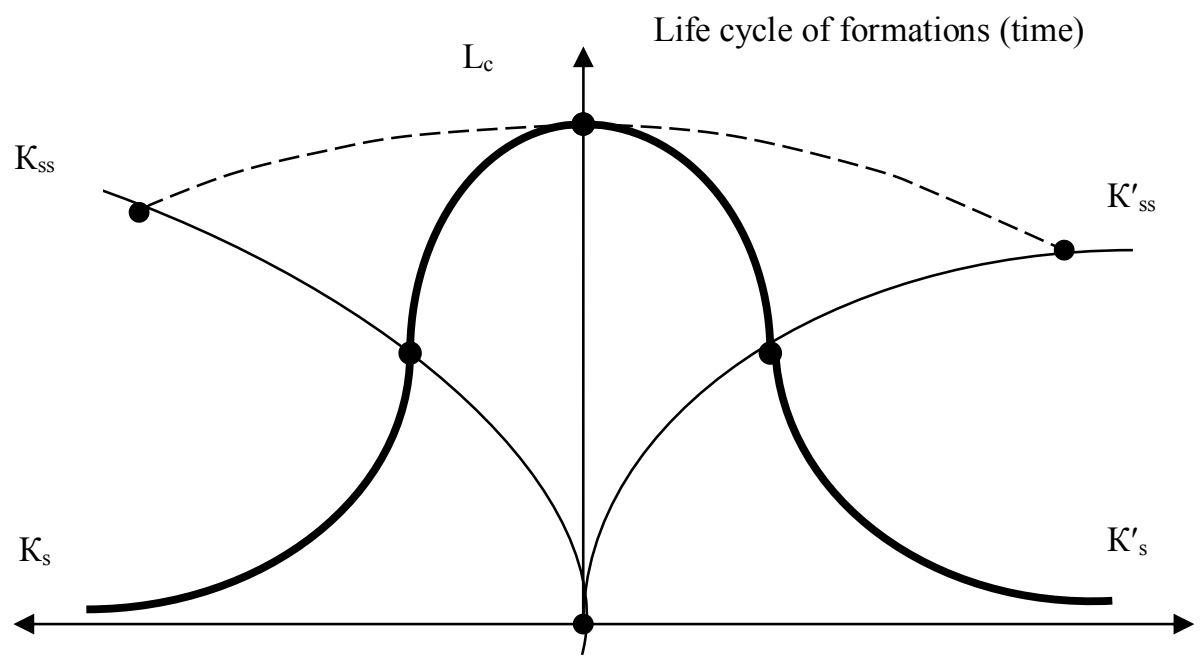

Fig. 1. Interaction of the life cycle of natural formations depending on the consumption of environmentally related energy $K_{s}$ to achieve a certain quality of their structures $K_{s}^{\mathrm{I}}$. 
b) Economic instruments for the sustainable development of construction systems that are used in the economy using conventional monetary measurement units (rubles, dollars, euros, etc.) instead of systemic measurement tools. At the same time the ratio between environmental and economic instruments causes certain risks throughout the entire life cycle of real estate. Therefore, it is proposed to determine the effectiveness of the real estate life cycle taking into account the combination of environmental and economic instruments [9].

Effective business results as the ratio of results and goals are achieved through a rational combination of entrepreneurship and creativity of the entrepreneur. Three arrows (selforganization, self-preservation and their coordination) must be combined with their system operation. The total energy of these arrows corresponds to their initial potential (Fig. 3) $[8,9]$.

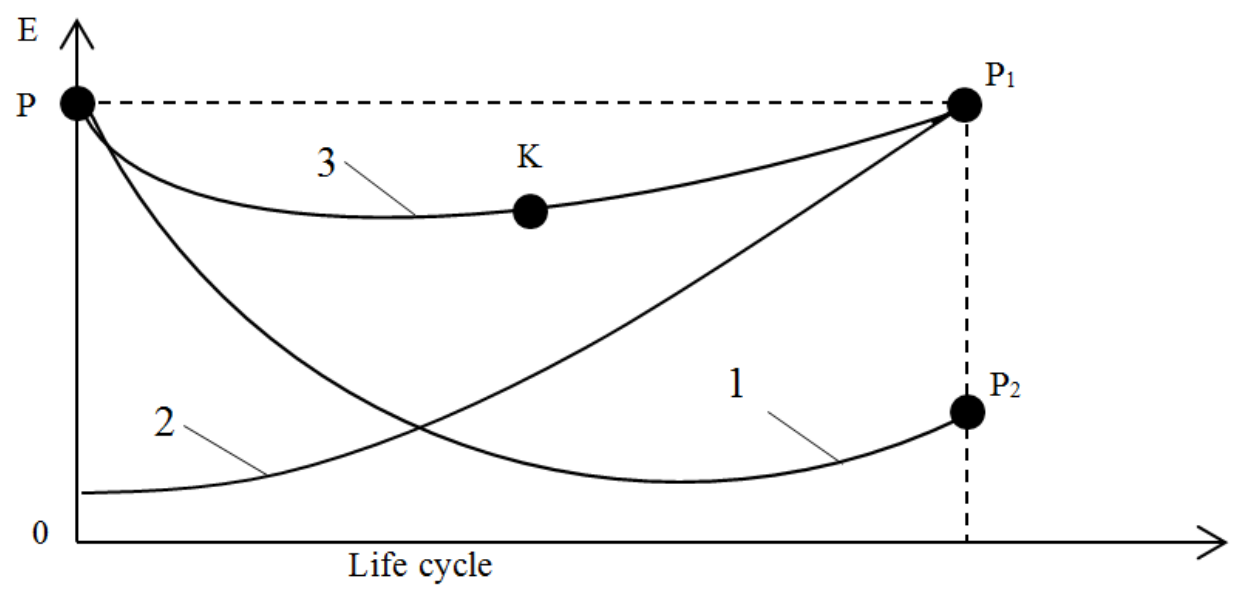

Fig. 2. Conditions for successful entrepreneurship activities: where $E$ is the energy of system state (for example, in the form of initial capacity) with its energy potential $P$ and the state of business idea development arrows; 1 - self-organization of business model (idea) structures; 2 - self-support (selfpreservation) of model integrity during its operation; 3 - entrepreneurial creative actions on arrows coordination [10].

\section{Results}

The area of effective work on the basis of construction technologies is the value, which combines positive effects and effects of self-destruction (wear and tear - degradation), as well as information content taking into account human genetics.

Based on this, the following methodological foundations for ensuring areas that can neutralize crises are adopted (Fig. 3). This area is found through the integral superposition of vectors that ensure the effective work of man and society in natural environments with the establishment of a self-sufficiency area for the sustainable development of their internal structures in natural environments. Deviation from the paths of possible development is allowed in the zones of maximum permissible changes in these parameters [11,12].

The first component - the K1 plane - should be the work of the internal state of the construction system, which is taken as the base $\sum \mathrm{Ki}$, with respect to which a change in all effects on the $\mathrm{K} 1, \mathrm{~K} 2$, and $\mathrm{K} 3$ planes is considered.

At the same time $\mathrm{K} 1$ is an environmental roadmap for construction operations, $\mathrm{K} 2$ is its economic map, and K3 is a roadmap of a man's genetic state with the highest degree of creative power of construction operations participants. All performance indicators should 
be expressed by the amount of energy that changes in the process of construction operations. For the purposes of this analysis the models shall include the following:

- Curves characterizing the growth of EI1 and a decrease in EII1 of energy consumed in ecological processes $\mathrm{K} 1$ at the point of its equality $\mathrm{O}$ and at points AI1, AII1 as permissible values of their life cycles.

- Curves characterizing the growth of EI2 and a decrease in EII2 of energy consumed in economic processes $\mathrm{K} 2$ at the point of its equality $\mathrm{O}$ and at the points of permissible values of their life cycles AI2, AII2.

- Curves characterizing the growth of EI3 and a decrease in EII3 of energy consumed in the process of the intellectual component of processes $\mathrm{K} 3$ at the point of its equality $\mathrm{O}$ and at the points of permissible values of life cycles AI3, AII3.

In all cases the change in the amount of energy consumed should not exceed the permissible fluctuation of factors. If we combine the states of the activity planes on the one side AII1, AII2, AII3, then it is clear that all deviations of activity parameters shall be considered in combination.

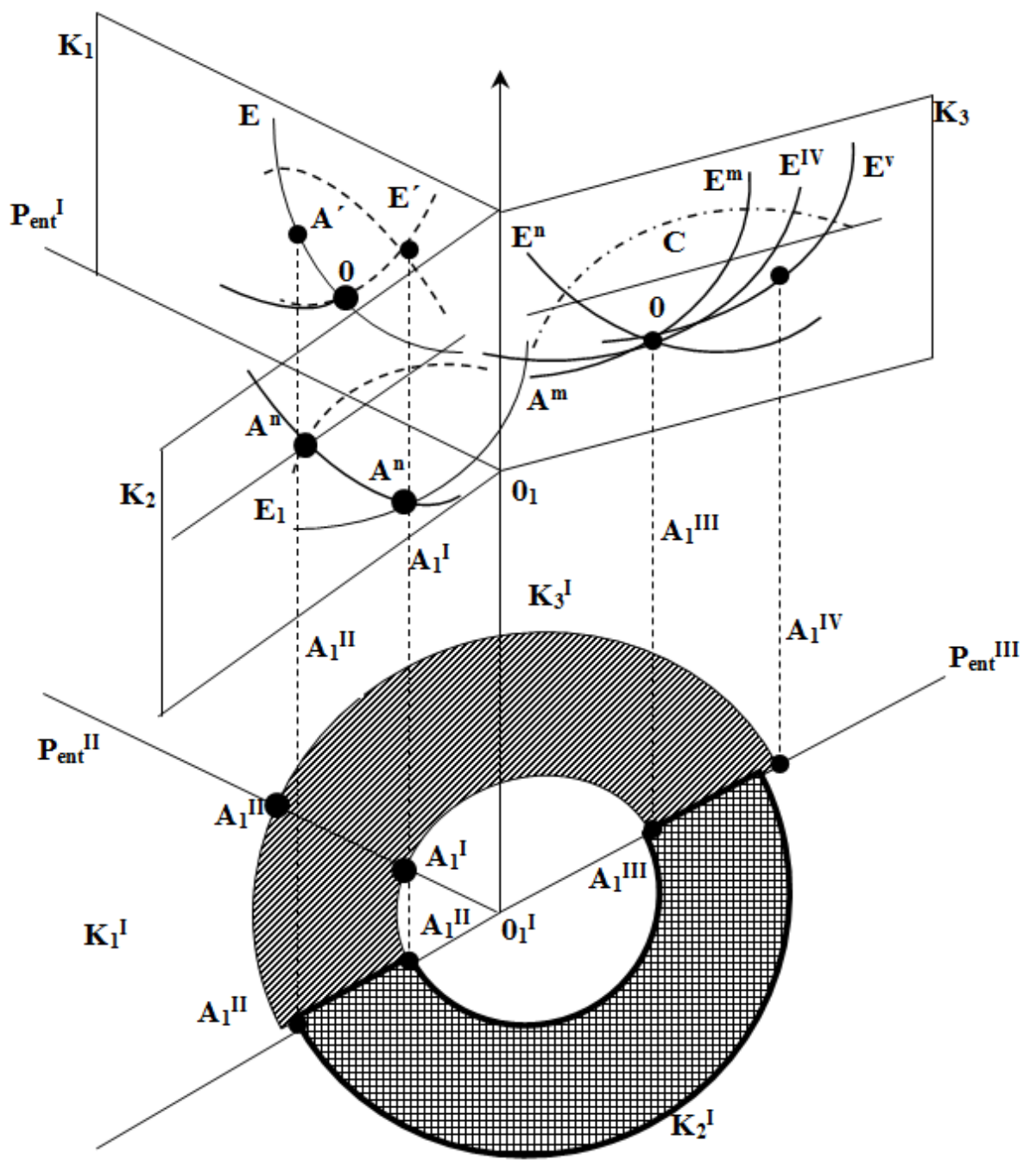

Fig. 3. Multifactor three-plane model of determining the area of rational sustainable development of men, society in construction operations in $\mathrm{A}_{1}{ }_{1}, \mathrm{~A}_{2}{ }_{2}, \mathrm{~A}^{\mathrm{III}} 3$ areas. 


\section{Discussion}

The economic and environmental effects of real estate construction make it possible to determine rational areas by synchronizing them. The degree of permissible deviations of these areas is determined by the maximum permissible changes in the parameters of ecological, economic, and intellectual processes [13].

A multidisciplinary multiplane model allows to determine the relationship between the resources used by all production process participants throughout the life cycle of the property. The proposed multifactor model allows us to find areas for the rational development of construction processes taking into account significant factors covering economy, ecology and potential intensity of labor resources [14]. Synchronization of these areas will allow to find rational zones of construction operations efficiency. Finding these zones will ensure the most rational use of natural resources taking into account production situations and characteristics of real estate [15].

\section{Conclusions}

The obtained model of choosing a rational combination of areas in the process of construction operations will allow reducing their risks and achieving maximum effects, which can be expressed in lowering real estate prices, shortening the time required to erect real estate, the efficient use of all types of resources, and increasing the life of real estate [16].

Models of construction operations synchronization taking into account their environmental, economic, technological, intellectual conditions can significantly increase their efficiency considering the variability within the permissible limits of the analyzed parameters.

\section{References}

1. L. Kauškale, I. Geipele Procedia Engineering 172, 505-512 (2017)

2. N.A. Vyatskova, B.B. Khrustalev, Journal of Economy and entrepreneurship 1(54), $404-413$ (2015)

3. L.V. Prykina, B.V. Prykin, Journal of Economy and entrepreneurship 1(54), 763 - 766 (2015)

4. S. Baronin, K. Kulakov, Journal of Advanced Research in Law and Economics 6(2), 291-298 (2015)

5. V. Nesnov, Technological mistakes and reserves of the government system (RoseDog Books, Pennsylvania, 2016)

6. C. Zhengdao Li, R.Y. Zhong, F. Xue, G. Xu, G. Qiping Shen, Journal of Cleaner Production 1651, 1048-1062 (2017)

7. L. Manukhina, L. Prykina, E3S Web of Conferences, 02140 (2019)

8. M. Kostyshak, M. Lunyakov, IOP Conference Series: Earth and Environmental Science 19 "Energy Management of Municipal Transportation Facilities and Transport, EMMFT 2017", 012183 (2017)

9. M. Josefy, R.M. Stevenson, Journal of Business Venturing (2018)

10. S. Botzem, L. Dobusch, Accounting, Organizations and Society 59, 31-43 (2017) 
11. A.I. Shinkevich, A.A. Lubnina, N.M. Chikisheva, L.M. Simonova, E.E. Alenina, B.B. Khrustalev, R.S. Sadykova, R.R. Kharisova, International Review of Management and Marketing 2(6), 219-224 (2016)

12. L. Manukhina, E3S Web of Conferences, 01069 (2019)

13. Global Hydrological Monitoring Industry Trends. Aguaticinformatics, http:/www.pages. aguaticinformatics.com/Water Report.htmal.

14. Oxford Dictionary. Retrieved from English Oxford Living Dictionaries, https://en.oxforddictionaries.com/definition/us/mompreneur

15. C. Ekinsmyth, International Journal of Entrepreneurial Behavior \& Research 19(5) (2011)

16. J. Larty, E. Hamilton, International Small Business Journal 3(29) (2011) 